\title{
Collective intentionality and the state theory of money
}

\author{
GEORGIOS PAPADOPOULOS \\ Aarhus University \\ University of Applied Arts Vienna
}

\begin{abstract}
The circulation of non-convertible currency and the source of its value raise important ontological questions that touch upon the conditions of its acceptance. The aim of this paper is to address such questions by illustrating how collective intentionality and constitutive declarations can be employed in order to develop an adequate ontological framework for explaining the emergence and the persistence of the current monetary standard. This analysis of money differs from that of mainstream commodity theory in that it argues against individualism, which traditionally underwrites both economic and philosophical analyses of money. The resulting ontology is based on an account of collective intentionality developed upon the "sharedness" of individual intentional states; this account supports the state theory of money, combining it with an ontological analysis of the state and its authority.
\end{abstract}

Keywords: collective intentionality, commodity theory of money, individualism, institutions, state theory of money

JEL Classification: B52, E40

\section{THE IMPORTANCE OF THE ONTOLOGY OF MONEY}

The ontology of money has been a fertile field for the application and the appraisal of philosophical theories of social existence; many social philosophers including Karl Marx, Georg Simmel, and Max Weber have developed elaborate theories about the emergence of money and its acceptance in economic transactions. More recently, the ontology of money has been an important question in the debate on the usefulness (or not) of "collective intentionality" (Gilbert 1989; Searle 1995), and further, has been used an illustration for the usefulness of the notion in the analysis of social existence (Hédoin 2013; Mäki 2005; Searle 1995, 
2005, 2010; Smit, et al. 2011; Tieffenbach 2010). The aim of the paper is twofold:

1. To contribute to the debate about collective intentionality by illustrating the explanatory merit of the notion for the social existence of money. This identifies money in the context of the current system of fiat money where its value is not intrinsic (or "hylic") and the state serves an important function as the ultimate guarantor of monetary value (Knapp 1924, 4). The proposed ontological account of money will update the state theory following the recent developments in social ontology.

2. To develop an account of collective intentionality built upon the notion of "sharedness" in order to propose an ontological framework for the state theory of money, explaining the preconditions for the social constitution and the mechanism of the collective acceptance of fiat money. ${ }^{2}$

The state theory argues that money is essentially created by the state, where currency is enacted by declaration independently of the inherent value of the objects used to represent currency. The state's reliance upon money and its fiduciary nature is consistent with its current monetary regime; non-convertible currency that is issued by the central bank - a state institution that may or may not be independent of the government-is intrinsically worthless. The central bank infuses the system with trust because it guarantees both the acceptability of money and the security of deposits by assuming the function of lender of last resort. According to the state theory, money falls back upon the rule of law, the system of taxation, and the ability of the state to enforce laws and taxation.

The appeal to state authority provides only a provisional explanation for the existence of money, i.e., for its instantiation in objects and practices. An analysis of the ontology of intrinsically worthless and nonconvertible money enacted by state authority should also provide an account of how this authority came to exist, and how it relates to the

\footnotetext{
${ }^{1}$ The description of collective intentionality as shared intentionality comes from Schmid (2003). It is different from Searle's account, which describes collective intentionality as the first-person plural-form of intentionality (Searle 2010, 43). Schmid reflects: "It is by now a well-established fact that intentionality is not exclusively a matter of the personal beliefs, desires and expectations of individuals. What makes our intentionality and our actions social is not just that from time to time, we make each other the object of our individual intentions or expectations. Rather, intentionality is in itself something human beings can share" (2003, 203; italics in the original).

${ }^{2}$ Mäki (2005) and Tieffenbach (2010) provide examples of an ontological analysis of money that also remains attached to methodological individualism.
} 
action and the attitudes of the individuals it regulates. Social ontology can provide the basis for the study of fiat money delineating a form of collective acceptance that is both able to carry the weight of fiat money and is consistent with a wider framework of analysis of social institutions, ${ }^{3}$ including the state. An account of collective intentionality that is based on the sharedness of collective intentional states-of which cannot be reduced to an aggregate of individual intentional states-can support both the existence of fiat money as well as the state that sanctions it. Here, collective intentionality is supplemented by the concept of "constitutive declaration" ${ }^{4}$ which, I argue, can resolve questions that concern the ontological foundation of the state theory of money-viz. where its institutional status as legal tender (not its value as a commodity) allows for its function.

In what follows, I elaborate the concepts of collective intentionality and constitutive declarations, highlighting their importance for the existence of social facts and for fiat money in particular. The analysis focuses on the relational character of collective intentionality, and on the explanatory advantage it provides over weaker notions of collective acceptance that are associated with methodological individualism (Meijers 2003; Schmid 2003). Furthermore, I illustrate the deficiencies of the individualist commodity theory, especially in relation to the current monetary standard where the acceptance of the means of exchange is not backed by a commodity guarantee. The problem of "group mind" is also addressed because it offers one of the main arguments against ontological collectivism (Searle 1990, 25). Finally, the proposed ontology of fiat money can account for the contribution of the state in the constitution and support of money, effectively filling an important explanatory gap within the state theory thereby countering the claim

\footnotetext{
${ }^{3}$ Institutions can be defined "as systems of established and prevalent social rules that structure social interactions" (Hodgson 2006, 2).

${ }^{4}$ Constitutive declarations are a special kind of speech act introduced by John Searle. Constitutive declarations constitute new social facts by representing speech acts as existing (Searle 2010,93). The term is going to be further developed in the next section.

${ }^{5}$ Schmid states that, "[w]here there is intentionality, it is said, there has to be somebody who 'has' it - the good old subject. Now if it is claimed that there is such a thing as collective intentionality, and that collective intentionality has to be distinguished from individual intentionality, the conclusion seems to force itself on us that it has to be not the single individuals, but the collectives themselves that 'have it'. And for collectives to have intentions, some sort of a 'collective mind', some 'group mind' seems to be required, something hovering over and above the mind of the individuals involved" (Schmid 2003, 214).
} 
that the state and its operation is just an all-purpose and ad hoc explanatory variable.

\section{BASIC CONCEPTS FOR THE ANALYSIS OF SOCIAL EXISTENCE; SOCIALITY, COLLECTIVE INTENTIONALITY, AND CONSTITUTIVE DECLARATIONS}

The starting point of an ontological analysis of money is the distinction of types of existence that characterize the social and the natural world, introduced by John Searle in The construction of social reality (Searle 1995, 5-13). According to Searle there is a fundamental distinction between natural facts and social facts. Natural facts "do not need us in any way"-their existence is independent of our representations about them. Social facts, on the other hand, are dependent on human consciousness for their representation. What defines sociality and social facts is a shared meaning supported by a shared language; the representations that we share about human interaction brings social phenomena into existence. ${ }^{6}$

Shared meaning is crystallized in collective intentionality: it is this collective intentionality that founds the proposed ontology of money, and thus explains the emergence and persistence of sociality and social facts. Intentionality is a broad philosophical concept that denotes more than just intention. It refers to the relation of the mind to the world, a relation towards external objects, states of affairs, and ideas. Candidates for intentional states can be any kind of mental representation of the world; representations are always about something or in reference to something (Searle 2010, 24). The relation of these mental representations to the world forms the basis of human consciousness, of human action, and allows for the constitution of social facts-this includes money. Collective intentional states employ the first-person plural form, meaning that collective intentional states express a "wemode" rather than the "I-mode" that characterizes individual intentionality (Searle 2010, 47). The first-person plural form places the individual's intention in relation to the collective of individuals to which collective intentionality applies (Davis 2003, 131). Collective intentionality here is understood as a shared we-intentionality and not as just an aggregate of individual intentional states; it is a particular type of intentionality that expresses an individual conviction and

\footnotetext{
${ }^{6}$ Searle writes, "[t]he key to understanding intentionality, at least for these simple cases, is representation in a very specific sense. The intentional state represents its condition of satisfaction" $(2010,29)$.
} 
participation in an intentional state that is shared by a collective of individuals. The members of we-intentionality share we-intentions as a collective, and the relations of the individual parties of collective intentionality-as parties that share the same we-intention-are integral to the content of we-intention. The relational character of the intentional states suggests a stronger, i.e., more collectivist, account of collective intentional states than Searle's, who subscribes to a subjective notion of collective intentionality (Searle 1995, 26). The simple example of two people going on a walk together can illuminate the relational character of attitudes that constitute collective intentionality. The shared weintention of each of the two individuals that go on a walk makes sense only if they both share the same we-intention to go for a walk. The shared intention creates a relation between the two individuals, and it is because of this relation that they go for a walk together. They act and perceive of their action as part of a common enterprise that they (both) acknowledge (Gilbert 1990, 7).

Collective intentionality is defined here in terms of shared meaning. Shared meaning founded on collectively recognized representations provides the foundation for social facts and for institutions, including money. We constitute the social environment on the basis of the shared representations and use these representations as the basis of our social interaction. The act of representation, when it is collectively acknowledged, generates new meanings and these meanings create new social facts that inform and condition human interaction. To return to the question of the ontology of money, money exists because we share representations that establish facts about meaning and the function of money-this is what gives it social significance in our everyday interactions. Social constitution can then be defined on the basis of a simple principle: social facts are established through our shared representations of them as existing, while these representations ascribe and reinforce the social significance of these facts.

The performative function of language, its ability to transform the world by ascribing meaning to facts, is presupposed by social constitution. John Austin developed a coherent account of how we can "do things with words" (Austin 1962). Searle expanded on Austin's theory of speech acts (Searle 1969) and introduced the concept of constitutive declarations. Constitutive declarations are a particular type 
of speech act that constitutes new social functions and social facts. ${ }^{7}$ Through these constitutive declarations we constitute social facts by declaring them to be the case. Constitutive declarations are public and official statements; they communicate the social significance of constituted facts and signal the authority that enacts these facts. Common examples of constitutive declarations include pronouncements of marriage and divorce (e.g., "I declare you husband and wife"), declarations of war, commencement and conclusion of sessions in official bodies such as court or parliament, and the like.

Constitutive declarations can be formalized as: "We (or I) make it the case by declaration that the Y status-function exists" (Searle 2010, 93). The formalization suggests that constitutive declarations need to be public and that their intended outcome is the social constitution of status-function. The public character of the constitutive declaration is important because the constituted status-functions need to be known (or at least knowable) to all the members of the collective, where the new status-function is enacted. Public acknowledgement does not entail that the constitutive declaration has to be performed verbally, or that it needs to be performed at all. Constitutive declarations are often formal rules that are made public by the appropriate authorities and are knowable, at least in principle, by all the affected parties. Statusfunctions are defined by a collectively acknowledged social representation, which in turn allows the fulfillment of a function. They are constituted by collective intentionality and they function by carrying deontic powers. Regarding the status of money, something underwrites the means of exchange, thereby enabling the process and fulfillment of economic transactions. New status-functions need to be acknowledged and endorsed by the collective, where the act of constitution is performed, in order to be effective. Only if the new representation that constitutes the status-function is shared by the collective will the declaration become successful. The success of constitutive declaration depends upon both public acknowledgment and the legitimacy of the declaration.

The legitimacy of constitutive declaration is supported by political authority, which is built upon an institutional structure that enables the

\footnotetext{
${ }^{7}$ Meijers states that, "[t]he remarkable consistency of Searle's project is also evident from the fact that social reality has been on his mind from Speech Acts to The Construction of Social Reality (1995). One of the revolutionary aspects of his theory of speech acts was the idea that speaking is acting in accordance with social rules. These rules not only regulate but also define linguistic utterances" $(2003,170)$.
} 
performance and enforcement of such constitutive declarations. The constitution of status-functions presupposes the existence of an institutional structure that regulates the process and defines the conditions for the enactment of constitutive declarations (Searle 2005, 9-10). A special authority is not only necessary to legitimize the constitutive declaration, it is also necessary for the enforcement of the consequences of the constitution of a new status-function. The special status that enables social constitution also contributes to the investment of the new status-functions with collective intentionality. For example, only the government (or only the president) can declare war, while only a public official or a priest can legitimize marriage or divorce. These two conditions, public recognition and proper authority, are necessary but not sufficient for the establishment of a new statusfunction; it is the collective intentionality of the public that enables the constitution of status-functions. Constitutive declarations articulate and communicate the content (denoted by shared linguistic-mental representations) of the new status-function that they establish; but, it is only if the public collectively intend the new status-function, will the act of constitution be successful.

Collective intentionality and the status-functions that collective intentionality supports are the outcome of the negotiation of agents with different viewpoints and interests that try to promote a particular representation of social reality. Authority can then be conceptualized as the ability to tap into the institutional and discursive power structures in order to impose new representations of reality, universalizing and effectively constituting reality. Collective intentionality is both the precondition and the outcome of such a universalization. The power to enforce constitutive declarations and secure the collective intentionality of the public translates as the power to enforce social facts. The stake of social antagonism is to constitute partisan viewpoints as the universal interpretations of social reality. Authority is necessary for the constitution of money; it inspires and reinforces the collective intentionality towards money, which underlies its emergence and persistence, and it aligns the expectations of all individual users toward a general acceptance of the dominant standard of abstract value.

\section{MONEY AND COLLECTIVE INTENTIONALITY}

Searle has made extensive use of money to illustrate his account of social ontology (Searle 1995, 2005, 2010). Even in the introduction of 
The construction of social reality (Searle 1995) money provides the starting point for the explication of the Searlean ontological framework. ${ }^{8}$ Money remains the focal point of debates about collective intentionality in the work of both proponents and critics of Searle's account of the ontology of money. The latter have looked into mainstream economics in an attempt to find counter-arguments against the relevance of collective intentionality for social constitution against claims of the irreducibility of collective intentionality, and against the two-tiered ontology that distinguishes the social from the natural (Smit, et al. 2011; Tieffenbach 2010). This paper, then, can be seen as a criticism of Searle - the analysis of collective intentionality vis-à-vis the institution of money is intended to identify a stronger account of collective intentionality and constitutive declarations that is built upon the idea of "sharedness" (Schmid 2003). The aim is to develop an ontological account of money that makes the state theory consistent with recent developments in social ontology (Papadopoulos 2009).

Money should not be conflated with the objects that represent money, be it commodities or intrinsically valueless currency (coins or notes), since the institution of money depends on the shared representations (the speech-enacted meanings) that define its institutional status. Currency is used as a means of payment only because of its status-function as money; its status-function informs the very attitudes and behaviors about it. It is thus by virtue of its statusfunction that money fulfills its institutional role. The invisible hand explanation of the emergence of money (Menger 1892) can be reformulated by using the format of constitutive declarations; a certain commodity becomes institutionalized as money when it assumes the status-function of a medium of exchange. A similar formulation can be constructed for the state theory of money (Knapp 1924). Legal tender issued by the political authority becomes money when they assume the status-function of a standard of value. Yet, at a specific point in time, those commodities-such as pre-weighted pieces of metal or bills of exchange-stop being used as and become standards of value and media of payment because they assume status-function. The political authority enacts and communicates the status-function of currency by inscribing an insignia to it, by supporting it with its power, and by enacting the

\footnotetext{
${ }^{8}$ Searle writes: "For example how can it be a completely objective fact that the bits of paper in my pocket are money, if something is money only because we believe it is money?" (1995, 2-3).
} 
necessary legal rules. All of these steps serve to enforce the collective intentionality of the users.

As explained above, money can be successfully constituted only when it is enacted and communicated by agents who have the right to do so. The right to issue money is reserved for the sovereign political authority, who guards the monopoly over the monetary system through legislation and the use of force. Political authority represents the community it governs, and the monopoly to issue money is exercised in the name of this community. The officially issued currency carries the insignia of this authority, which Searle refers to as "status indicators" (Searle 1995, 119)-these symbols represent the status-function of the currency as the official legal tender. The symbolism of the insignia is intended to communicate the status-function of money, communicating that money will be accepted as payment, including the settlement of taxes. Authoritative support, which is expressed both symbolically and legally, injects money with the collective intentionality that it enjoys both as the issuer of money and more generally as the sovereign political agent within the community.

\section{THE INSUFFICIENCY OF INDIVIDUALISM AS THE ONTOLOGICAL FOUNDATION OF THE CURRENT MONETARY STANDARD}

One of the main problems of the commodity theory of money is its commitment to individualism (both ontological and methodological); by consequence it is unable to explain the emergence and persistence of money in the absence of a commodity guarantee. The individualistic methodology was established as the mainstream approach during the Methodenstreit (which translates as 'conflict about methods'). During this time Menger published his famous article on money (Menger 1892), which subsequently influenced debates between the proponents of the commodity theory of money and the state theory of money. Commodity theorists argued that the use of money and the (indirect) exchanges of goods are the outcome of the individual maximizing behavior. The rational reconstruction of the emergence of money offered by Carl Menger (1892), along with the expansion of his model in neoclassical economics, has provided a consistent account of one possible, albeit historically and anthropologically unsupported, ${ }^{9}$ mechanism for the constitution of commodity money as the universally accepted means of exchange. The standard invisible hand explanation may be sufficient for

\footnotetext{
${ }^{9}$ See Pryor 1977; Wray 1990; Goodhart 1998; and Ingham 2004.
} 
the study of commodity money, but it is not readily applicable in the current monetary standard, where money is not backed by a commodity guarantee. The Mengerian account was not intended to, and cannot, explain why individuals will accept worthless, token-money in exchange for valuable commodities, or further, how such a monetary standard could emerge. An intrinsically worthless means of exchange is vulnerable to the "free rider" problem because, as long as it remains intrinsically valueless, individuals will be better off if others exchange their goods for intrinsically "worthless" money with them, while they exchange their goods only for other goods. ${ }^{10}$ The positive feedback (viz. the reduction of transaction costs by a commonly accepted means of exchange that instigates the emergence commodity money according to the theory) is canceled out when there is no commodity guarantee, so a means of exchange cannot arise spontaneously. Further, even if there were a case in which a universal medium of exchange was not backed by a commodity (say through the suspension of convertibility in a preexisting commodity standard) its persistence would remain a problem without the existence of an external mechanism to ensure compliance.

One solution to this problem is presented by Nobuhiro Kiyotaki and Randall Wright (1989, 1991, 1993), who argue that for a fiat money equilibrium to persist it is sufficient that each agent believes that all other agents will continue to accept fiat money for the commodities they want to exchange. ${ }^{11}$ The problem is that the postulated collective acceptance is not resilient if it is understood as an aggregate of individual beliefs and thus cannot be reconciled with methodological individualism. Indeed, Kiyotaki and Wright presuppose an individual belief about a collective belief ("I believe that everybody believes that money is and will remain acceptable"). Nevertheless, the individual belief of every agent is predicated on and conditioned by the collective belief, the status of which is contested in the framework of

\footnotetext{
${ }^{10}$ There are two ways to facilitate fiat exchange in such a setting. Either "(1) by imposing a boundary condition, or (2) avoiding the boundary condition by pushing it away to infinity. Both are devices to circumvent the unraveling of the monetary equilibrium through backward induction" (Kovenock and De Vries 2002, 147). The boundary condition can be a policing authority or the assumption that individuals will continue to accept money, come what may.

${ }^{11}$ Kiyotaki and Wright note that, "[t]o this end, we now suppose that everyone believes that others will accept fiat money and ask if this could be an equilibrium" (1989, 493; emphasis in the original). This is a familiar strategy in overcoming the problem of explaining the value of fiat money by assuming it. Sidrauski, in one of the first attempts to incorporate money in general equilibrium modeling, assumed that real cash balances yield positive utility (Sidrauski 1967, 535).
} 
methodological individualism, especially since the beliefs of every individual are derived from, rather than constitutive of, this collective belief. Hence, the problem of the emergence of fiat money remains unsolved. Kiyotaki and Wright, and methodological individualists in general, are unable to answer the question of how such collective beliefs about the general acceptability of and faith in fiat money can arise and persist (remember that the function of fiat money as a means of exchange is undermined by free riding). Fiat money cannot emerge on the individual level, since the individual belief of each and every user of money presupposes a collective agreement about the acceptance of money by all other users. ${ }^{12}$ To put it more clearly, the establishment of the collective acceptance of money as merely an aggregation of individual beliefs is not possible because these individual beliefs presuppose the collective recognition needed to constitute it. The problem can only be circumvented with the postulation of a collective recognition of money shared by all individual agents in the market. The inability of methodological individualism to account for the emergence and persistence of fiat money, one of the most important economic institutions, indicates that the commitment to ontological individualism should be reconsidered, at least as far as the underlying philosophy of economic inquiry is concerned. In the next section I will defend a collectivist ontology based on collective intentionality and constitutive declarations. This counters any attempts to reduce the proposed ontological account to some kind of individualism, thereby strengthening the proposed framework for the explanation of the emergence and persistence of state sanctioned money.

\section{THE IRREDUCIBILITY OF COLLECTIVE INTENTIONALITY}

The foundation of the proposed ontology of fiat money, and more generally of social institutions, is a kind of collective intentionality based on "sharedness"-this is the strong collective intentionality that I have pursued thus far. As I argued above, such an account of collective acceptance is necessary for the persistence of a fiat money equilibrium.

\footnotetext{
${ }^{12}$ Searle describes it as follows: "There is a deep reason why collective intentionality cannot be reduced to individual intentionality. The problem with believing that you believe that I believe, etc., and you believing that I believe that you believe, etc., is that it does not add up to a sense of collectivity. No set of 'I Consciousnesses', even supplemented with beliefs, adds up to a 'We Consciousness'. The crucial element in collective intentionality is a sense of doing (wanting, believing, etc.) something together, and the individual intentionality that each person has is derived from the collective intentionality they share" (Searle 1995, 24-25, italics in the original).
} 
In this section I am going to argue against attempts to reduce collective intentionality into individual intentionality, or to individual intentionality in conjunction with other individual attitudes (like common knowledge). By establishing that collective intentionality cannot be reduced to individual attitudes, the analysis of money emerges as substantially different from the account offered by the commodity theory; furthermore, it establishes how a genuinely collectivist attitude, like the proposed version of collective intentionality based on sharedness (argued for above; see Schmid 2003) is necessary for the emergence and persistence of the institution of money.

Collective intentionality requires at least two parties in order for weintentions to be genuine. Sharing the same we-intention puts the parties in a relation, a relation that is itself part of the content of we-intentions. The fact that the parties of collective intention are in relation is indicated by the use of the first-person plural form of the shared intention; the "we-mode" of collective intentionality suggests that I see myself as part of a collective that intends in concert, and if the weintention is correct, I am actually part of this collective of individuals intending together. The web of relations where the individual is placed by a collectively shared intention is internal to the collective intention because the propositional content of the we-intention describes the intention of a collective, and thus the content of the we-intention makes sense only in the context of the internal relations of this collective. To wit, collective intentionality and the relations of the individual parties are mutually constituted; the parties of the we-intention are related in virtue of the we-intention they share, and the propositional content of the we-intention makes sense only on the basis of these relations. If this claim is true, a reduction of collective intentionality to individual intention(s) is not possible because these essential relations will remain unaccounted for. The underlying conviction behind this claim is that it is the relations defined by and defining of collective intentionality that carry the act of social constitution..$^{13}$

The beliefs that underlie the existence and circulation of money can be reconstructed as an expression of the collective intentionality of the

\footnotetext{
${ }^{13}$ Hodgson states, that "[t]he social world, by virtue of the fact that it is social, must involve such interactive relations. The term 'social' here is used in a broad sense, to encompass phenomena that are examined in economics, as well as other social sciences. In the social context all relations between individuals are causal and interactive, at least in the sense that in maintaining these relations with others, individuals are affected by their (partial) awareness of them and different actions may be enabled" (Hodgson 2007, 212).
} 
users, e.g., "I believe that we recognize $X$ as the standard abstract of value", or "I believe that we accept X as a means of payment". Such weintentions cannot be reduced to an aggregate of I-intentions because they depend on a shared commitment to the acceptance of money, as well as to a wider framework of economic relations that define the market system of monetary exchange. These relations are part of the collective we-intention that supports money, not only because they constitute the market but also because they define the very notions of "standard of value" and "means of payment". Money presupposes division of labor, markets, individual producers and consumers with specific attitudes and expectations about money and about the behavior of others towards money. The acceptance of the institution of money situates the individual in a web of economic relations with other producers, consumers and authorities that issue the money. These relations are what give money its social significance and identity. ${ }^{14}$

The content of the we-intention that each individual holds as a party involved in collective intentionality is derived by the content of the shared we-intention of the collective. Sharing collective intentions does not depend on mere individual awareness of the intentional states. Awareness of one's sharing of a collective representation is not a sufficient condition for collective intentionality because one can mistakenly think that one is part of a collective intentional state that nobody else shares. If somebody we-intends to go for a walk with somebody else, the we-intention is justified if both partners intend to go for a walk; the propositional content of each individual's we-intention is dependent on and derives its validity from the propositional content of the shared we-intention. If we think correctly of ourselves as members of a collective sharing a collective intention, it is because we actually are part of this collective that shares this collective intention, and not the other way around (Schmid 2003, 212). Subjective individualism, ${ }^{15}$ the

\footnotetext{
${ }^{14}$ Ingham clarifies that the "[m]onetary systems are the result of the long term historical development of a complex structure of social relations and practices which cannot be grasped by of neoclassicism's methodology. In this respect, Smithin has observed that "the micro-foundations of standard monetary theory have been left extremely weak" (Smithin 1994, 14). In fact, we need to go further: money cannot have "micro-foundations" if these are sought exclusively in the formal deductive model of the individual agent's rational choice of holding a "veil" or "lubricant" as simple medium in a "real" exchange economy" $(1996,516)$.

${ }^{15}$ I shall use the term subjective individualism, following Hans Bernhard Schmid, in contrast to reductive or formal individualism, where all collective or holistic facts can and should be reduced to aggregates of individual attitudes or behavior. Schmid states: "Subjective individualism does not limit intentionality to the singular form, but
} 
ontology that supports Searle's weaker conception of collective intentionality, may lead to the opposite paradoxical conclusion that collective intentionality constitutes the collective that is expressed by the 'we' for every individual that holds a we-intention even in the case when the individual in question is the only one that holds the weintention. The content and the validity of the individual we-intention is dependent on and derived from the shared we-intention. Individual beliefs about money presuppose a collective belief about money and the individual belief of every agent is predicated on and conditioned by the collective belief about the acceptability of money. Rephrasing the claim once more for the benefit of clarity, the constitution of the collective acceptance of money as the aggregation of individual beliefs of acceptance is not possible because individual beliefs presuppose the collective acceptance they are supposed to constitute.

Money is enacted through a constitutive declaration made by the sovereign political authority, and its constitution aligns the expectation of individual agents; this inspires a shared collective intentionality that underlies the individual we-attitudes towards money. Reductive or formal individualism, i.e., the attempts to reduce collective intentional states to aggregates of individual attitudes, is insufficient because the relations between the individual bearers of collective intentionality cannot be included into individual intentionality. Similarly, subjective individualism, which suggests that collective intentionality could exist in isolated individual minds, is also untenable. Furthermore, the internalist account of collective intentionality is untenable because collective intentional states (we-intentions) rely for their validity on a collective intention that is shared by the other parties.

Collective intentionality, like all other types of intentionality, is part of the spectrum of conscious states; so if collective intentionality is not reducible to individual intentionality, an issue arises as to the location of this intentional state. It may seem plausible to argue that collective intentionality entails the existence of a group mind (a 'we-mind') or a collective spirit that houses the collective intention. The fact that weintentions are shared does not necessarily suggest that collectives have a unifying mind where the shared collective intentionality is actually located. ${ }^{16}$ I propose that collective intentionality is located

restricts the class of possible subjects or 'bearers' of intentions to single individuals" (2003, 206).

${ }^{16}$ Schmid here states that, "[c]ollective intentions, however, do not have a single subject. They have many. Thus the group mind is nothing we should be afraid of. It is 
simultaneously in the minds (and the brains) of all the individuals that share the collective intentional state and that the interrelation of the minds and of the individuals is integral to the collective intentionality that the individuals share. Sharedness is a matter of relations between minds that transcends the physical boundaries of each individual, forming a network of minds and intentional states (Meijers 2003, 174). The sharedness and relationality of collective intentions is supported by the basic sense of collectivity that is common to all individuals; it permits the sharing of we-intentions. It is this sharedness that allows for social facts like money to exist and for the successful operation of our communities.

\section{COLLECTIVE INTENTIONALITY AND THE STATE}

The state theory of money uses the political authority of the state and the subsequent ability to levy taxes, to explain the emergence and persistence of fiat money. In order to complete the proposed ontological framework, it is necessary to show that state authority is not an ad-hoc explanation or a 'black box' without social foundations. It is therefore necessary to illustrate how it fits in the overall ontological framework of collective intentionality and constitutive declarations. The state enjoys the monopoly of power over a designated geographical territory as well as over the population of its subjects. The monopoly of power, taxation and fiat money indicates that the state is a very special institution; nevertheless, its authority and its sovereignty do not relieve the state from its dependence on society. The state is dependent on the collective intentions that constitute it-the shared representations about what the state is and does-and it is its status-function that organizes the relation to its subjects. State authority should be analyzed under the same ontological framework as money, comprised of collective intentions and constitutive declarations. ${ }^{17}$ The structure of governance is constituted on the basis of a fundamental intelligibility of political

merely a distorted individualistic image of a non-individualistic, holistic concept of the mind. Collective intentions are not intentions of the kind anybody has-not single individuals, and not some super-agent. For collective intentionality is not subjective. It is relational" $(2003,216)$.

${ }_{17}$ Steinberger notes that "[w]hile particular states may differ [...] all states are essentially similar with respect to their proper scope of action, the nature of their authority, and their basic principle of organization. To demonstrate that this is in fact true and to show what it actually says about a state's activity, authority and internal constitution, is largely what it means to pursue an ontological theory of the state" $(2004,35)$. 
action, i.e., a set of principles that define the expectations of the citizens in their relations to it and inform all aspects of social existence that have some relation to governance and regulation. ${ }^{18}$

In Leviathan, Thomas Hobbes defined the state in terms of sovereignty and order; since Hobbes, sovereignty remains the single most important defining characteristic of its identity (Hobbes 2012 [1651]). The status-function of the state is its ability to establish and maintain order over a specific geographical territory in virtue of its sovereignty in this geographical area. The monopoly over violence and the exclusive authority to regulate the use of force are consequences of its status-function as the sovereign enforcer of public order. The state can trump the actions of all other institutions and individuals precisely because of its monopoly over violence-this is what establishes its position in the social world making it the most powerful of all institutions. The special position of the state in the social hierarchy is already anticipated by its status-function as the sovereign institution: it is entrusted with maintaining order among all agents, including other institutions and organizations. The evolution of the state is a process of constant negotiation of the idea of state authority and its implications for governance. The state can expand (or limit) the scope of the exercise of its legitimate authority by constantly revising the content of the status-function upon which its legitimate authority is constituted. The stability and the adaptability of democratic societies lies in their capacity to constantly reinvent political purpose, to keep the authority of the government in check through regular elections that reinforce the collective intentions of the citizens in an evolving system of governance.

The collective intentionality of the citizens constitutes and regulates the state on the basis of the shared representations of what state authority and state power are, delineating the scope and the scale of it actions. Consequently, the efficacy of state actions and authority are

\footnotetext{
${ }^{18}$ Steinberger further clarifies: "Indeed the state is nothing more than the authoritative manifestation of an entire way of life, reflecting as such, the full gamut of judgements about how things in the world-all things in the world-really are. It articulates and codifies a structure of truth about the nature of reality, i.e., the shared, typically tacit assumptions, presuppositions, theories, commitments and understandings on the basis of which individual members of the society are able to communicate intelligibly and interact coherently. Indeed, the propositions that constitute the idea of the state pertain not to this or that sector of society, but to the full range of social enterprises; it is composed of the notions of how institutional conflicts within the society are to be resolved for the good of society; it is a comprehensive structure of ideas that functions as a kind of rule-book of last resort, a final court of appeal on the basis of which all social disputes are evaluated [...]" $(2004,22)$.
} 
conditioned by the common understanding of the identity of the state and the perceived legitimacy of its authority. As long as the actions of the state are an expression of its institutional status, the collective intentions of its citizens and the legitimacy of the state actions are safe. If state policies transcend the limits posed by the shared representation of the state and its functions, the state risks losing (some of) its authority which is constituted on collective intentionality. The state is an instantiation of the shared representation of how authority and power are organized and exercised; its legitimacy can be analyzed by the shared intentions that constitute its status as an authority.

Collective intentionality and sovereignty are in a relation of mutual dependence. The sovereignty of the state depends on the collective intentionality of the society at the same time as the state can use its sovereignty not just to inspire but also to enforce the collective intentionality, by the exercise of its power; this what Searle means when he says that, "power is a system of status-functions and thus rests on collective acceptance, but the collective acceptance, though not itself based on violence can continue to function only if there is a permanent threat of violence in the form of the military and the police" $(2003,204)$. The possibility to enforce collective intentionality through coercion undermines the proposition that the individual attitudes clustered collectively provide the source of all social facts and status-functions. The dissolution of individual autonomy is a consequence of the statusfunction of the state. The individual recognizes the state as the locus of sovereign authority that maintains order; consequently, the individual accepts his/her position as subject of the state's power on the condition that the exercise of power is legitimate. Faced with the organized apparatus of political control and the monopoly of violence of the state, the individual may feel, and in fact be, powerless. The community may indeed be the source of all power; but for the state to maintain order it is necessary that each individual does not realize that the existence and authority of the state are dependent also on his or her collective intentionality (Searle 2003).

The same asymmetry of power between the individual and the state is characteristic of their economic and monetary relations. The credit relation between state and society, and the subsequent enforcement of the official currency is not voluntary, but is founded on the monopoly of the state and its ability to enforce taxation upon the citizens. Taxation is the consequence of the sovereignty of the state in the economic domain; 
and with taxation emerges money and its acceptance by the public (Ingham 2004, 47-48). The necessity for the individual to earn income in the form of officially sanctioned currency in order to pay his/her taxes makes currency not only acceptable but desirable as a means of payment. The prerogative of the state to demand the payment of taxes and moreover to demand taxes in the tender that the state itself issues, lies in the center of the monetary system. Taxes cancel the debt that the issue of money creates: a loan of the issuing authority towards the bearers of money.

The source of economic sovereignty remains the product of collective intentionality of the public towards power and money; a collective intentionality that presupposes the acknowledgment not only of the monopoly of violence of the sovereign authority but also of its sovereign rights to sanction taxation and money. The state is also constrained by the attitudes of its subjects, i.e., by their expectations about the acceptability and value of money in the future. Tampering with the monetary system or imposing taxes beyond a point of considerable fairness by the public can lead to the loss of reliability of the state institutions; this can lead to increasing costs of enforcement, to inflation, to capital flight and the parallel circulation of other currencies. The attitudes of the public when expressed in concert can challenge the monetary sovereignty of the state in the same capacity that they support the existence and the circulation of money.

\section{CONCLUSIONS}

This paper outlined the ontological structure that underlies the emergence and persistence of fiat money based on the notions of constitutive declarations, collective intentionality, and sharedness, by illustrating the usefulness of these concepts for social analysis. The resulting theoretical framework is in many respects different from the usual treatment of money in collective intentionality literature (Hédoin 2013; Searle 1995, 2005; Smit, et al. 2011; Tieffenbach 2010). The underlying state theory of money is at odds with the concept of money as a means of exchange that emerges as the unintended consequence of the behavior of utility maximizing individuals. At the same time, the definition of collective intentionality as a relational and shared weattitude that exists in interrelated individual minds contradicts the individualistic accounts of the exchange theory of money in analytic philosophy (Meijers 2003; Schmid 2003). The resulting ontology of 
money can support the state theory of money, while it provides an ontological analysis of the state and its authority that is consistent with collective intentionality and constitutive declarations. The relation between state authority and the acceptability of money-a relation that carries the burden of explaining the emergence and persistence of money for the state theory of money-provides an important gap in the ontology of the theory.

\section{REFERENCES}

Austin, John L. 1962. How to do things with words. Oxford: Clarendon Press.

Davis, John B. 2003. The theory of the individual in economics. London: Routledge.

Gilbert, Margaret. 1989. On social facts. Princeton (NJ): Princeton University Press.

Gilbert, Margaret. 1990. Walking together: a paradigmatic social phenomenon. Midwest Studies of Philosophy, 15 (1): 1-14.

Goodhart, Charles A. E. 1998. The two concepts of money: implications for the analysis of optimal currency areas. European Journal of Political Economy, 14 (3): 407-432.

Hédoin, Cyril. 2013. Collective intentionality in economics: making Searle's theory of institutional facts relevant for game theory. Erasmus Journal for Philosophy and Economics, 6 (1): 1-27.

Hobbes, Thomas. 2012 [1651]. Leviathan. London: Penguin.

Hodgson, Geoffrey. 2006. What are institutions? Journal of Economic Issues, 40 (1): 124.

Hodgson, Geoffrey. 2007. Meanings of methodological individualism. Journal of Economic Methodology, 14 (2): 211-226.

Ingham, Geoffrey. 1996. Money is a social relation. Review of Social Economy, 54 (4): 507-528.

Ingham, Geoffrey. 2004. The nature of money. London: Polity.

Kiyotaki, Nobuhiro, and Randall Wright. 1989. On money as a medium of exchange. Journal of Political Economy, 97 (4): 927-954.

Kiyotaki, Nobuhiro, and Randall Wright. 1991. A contribution to the pure theory of money. Journal of Economic Theory, 53 (2): 215-235.

Kiyotaki, Nobuhiro, and Randall Wright. 1993. A search theoretic approach to the pure theory of money. American Economic Review, 83 (1): 63-77.

Knapp, Georg F. 1924. The state theory of money. London: Macmillan.

Kovenock, Dan, and Casper De Vries. 2002. Fiat exchange in finite economies. Economic Inquiry, 40 (2): 147-157.

Kroes, Peter, and Anthonie W. M. Meijers. 2003. The dual nature of technical artefacts. Studies in History and Philosophy of Science Part A, 37 (1): 1-4.

Meijers, Anthonie W. M. 2003. Can collective intentionality be individualized? American Journal of Sociology, 62 (1): 167-183.

Menger, Carl. 1892. On the origin of money. The Economic Journal, 2 (6): 239-255.

Papadopoulos, Georgios. 2009. Between rules and power: money as an institution sanctioned by political authority. Journal of Economic Issues, 43 (4): 951-969.

Pryor, Frederic L. 1997. The origins of money. Journal of Money, Credit and Banking, 9 (3): 391-409. 
Schmid, Hans Bernhard. 2003. Can brains in vats think as a team? Philosophical Explorations, 6 (3): 201-218.

Searle, John. 1969. Speech acts: an essay in the philosophy of language. Cambridge: Cambridge University Press.

Searle, John. 1995. The construction of social reality. New York: Free Press.

Searle, John. 2003. Political power and social ontology. In Socializing metaphysics: the nature of social reality, ed. Frederick F. Schmitt. Lanham (MD): Rowman and Littlefield Publishers, 195-210.

Searle, John. 2005. What is an institution? Journal of Institutional Economics, 1 (1): 1-22.

Searle, John. 2010. Making the social world. Oxford: Oxford University Press.

Sidrauski, Miguel. 1967. Rational choice and patterns of growth in a monetary economy. The American Economic Review, 57 (2): 534-544.

Smit, J. P., Filip Buekens, and Stan du Plessis. 2011. What is money? An alternative to Searle's institutional facts. Economics and Philosophy, 27 (1): 1-22.

Smithin, John N. 1994. Controversies in monetary economics: ideas, issues and policy. Aldershot: Edward Elgar.

Steinberger, Peter J. 2004. The idea of the state. Cambridge: Cambridge University Press.

Tieffenbach, Emma. 2010. Searle and Menger on money. Philosophy of the Social Sciences, 40 (2): 191-212.

Georgios Papadopoulos has completed his $\mathrm{PhD}$ at the Erasmus University Rotterdam. Currently he is a visiting researcher at the department of aesthetics and communication at the Aarhus University and the University of Applied Arts in Vienna.

Contact e-mail: <languagegames@gmail.com> 